\title{
BIOSYNTHESIS OF GLYCOGEN FROM URIDINE DIPHOSPHATE GLUCOSE ${ }^{1}$
}

\section{F. Leloir, J. M. Olavarría,2 Sara H. Goldemberg ${ }^{3}$ and H. Carminatti}

Instituto de Investigaciones Bioquimicas, Fundacion Campomar and Facultad de Ciencias Exactas y Naturales, Buenos Aires, Argentina.

\section{INTRODUCTION}

The biosynthesis of glycogen from UDPG 5 with a liver enzyme has been reported previously (1). The reaction has been investigated further using a partially purified preparation form rat muscle with which the general properties of the system have been studied.

\section{METHODS}

\section{Analytical}

Glycogen was estimated by the pheirol-sulfuric acid method (2), after digestion with $\mathrm{KOH}$ and ethanol precipitation (3). A sample of glycogen prepared as described by Somogyi (4) was used as standard. Its concentration was checked against glucose using the anthrone method (5). UDP was estimated as described by Cabib and Leloir (6), but halving the amounts of reagents. UDPG was measured spectrophotometrically with a partially purified UDPG dehydrogenase (7). Phosphorylase was estimated as $d i$ scribed by Cori et al. (8). Protein was measured by the methods of Kunitz and McDonald (9) and of Warburg and Christian (10). Amylase activity was determined under the same conditions as the glycogen-forming enzyme but without UDPG or G-6-P. After deprcieinization with $\mathrm{Ba}(\mathrm{OH})_{2}$ and $\mathrm{ZnSO}_{4}$, the reducing substances were measured according to Park and Johnson (11). G-6-P was estimated spectrophotometrically (12). Radioactivity was measured with a gas-flow counter. Radioactive sugars in paper chromatograms were located with a silver reagent '(13) and then eluted, plated, and counted. Approximately half of the added counts were detected after this treatment.

1 This investigation was supported in part by a research grant (No G-3442) from the National Institutes of Health. grant (No G-3442) from the
U.S. Public Health Service.

2 Fellow of the Consejo Nacional de Invtstigaciones Científicas y Técnicas.

3 Investigator of the Instituto Nacionai de Microbiología.

4 Investigador of the Comisión Nacional de Energía Atómica. mica.

5 Abreviations used: UDPG: uridine diphosphate glucose; UDP; uridine diphosphate; G-I-P: glucose-1-phosphate; G.6-P: glucose-6-phosphate; Tris tris (hydroxy methly) aminometha ne; EDTA: ethylenediamine tetraacetate.

\section{Substrates}

UDPG was isolated from yeast ast described by Pontis et al. (14). UDPG labeled in the glucose moiety was prepared by incubating C14G-6-P with UDPG and a crude Saccharomyces fragilis extract (15) and was purified by paper chromatography.

\section{Enzymes}

The method of Ballou and Luck. (16) was used for the preparation of wheat B-amylase and that of Cori et al. (8) for phosphoryliase. A crude preparation of maltase was obtained as described by Weidenhagen (17) and dialyzed.

\section{Assay of the Glycogen-Forming Enzyme}

The standard reaction mixture contained 0.23 $\mu$ mole UDPG, $0.5 \mu$ mole G-6-P, $0.4 \mathrm{mg}$. giycogen, $3.75 \mu$ moles Tris-maleate buffer of $\mathrm{pH} 8.5,0.25$ $\mu$ mole EDTA, and enzyme, in a final volume of 0.05 ml. Incubations were carried out at $37^{\circ}$ for $30 \mathrm{~min}$. The reaction was stopped by heating for $1 \mathrm{~min}$. in boiling water, and the UDP formeit was measured. Under the conditions of the test, added UDP did not disappear on incubation with crude or purified muscle extracts.

The initial rate of reaction was calculated from a two or three-point time curve by applying the equation for first-order reactions and extrapolating the value of $k$ to zero time

\section{Preparation of the Enzyme}

Rlat muscle was used in most of the experiments. Only a small part of the activity was extracted with water from minced muscle. In order to obtain active extracts, it was necessary to homogenize the tissue thoroughly with a blendor. The extraction was usually carried out with water. With phosphate or pyrophosphate buffers the yield was slightly higher, but móre inactive protein was extracted. The enzyme could be precipitated from the aqueous extracts either with 0.41 saturated ammonium sulfate or by adjusting the pH to 5.8-6.0.

The procedure which was used in most of the preparations was as follows. The muscles from two rats (about $55 \mathrm{~g}$.) were cooled, minoed, suspended in 3 vol. of cold water, and homogenized for 2-3 min. in a Waring blendor. The homogenate was imme- 
diately centrifuged at $12,000 \times \mathrm{g}$ for $10 \mathrm{~min}$. When this procedure was carried out quickly and at low tempenature, the $\mathrm{pH}$ did not drop below 0.5

The supernatant crude extract was divided into two portions. One (about $1 / 4$ ) was heated at $100^{\circ}$ for $5 \mathrm{~min}$., and the precipitate was removed by centrifugation. The rest of the supernatant fluid (its volume is represented as $v$ in he following) was acidified to $\mathrm{pH}$ 5.8-6.0 (chlorophenol red as indicator), and after $15 \mathrm{~min}$. at $0^{\circ}$ was centrifuged at $24,500 \times g$ for $10 \mathrm{~min}$. The precipitatc was suspended in water, adjusted to $\mathrm{pH}$ 5.8-6.0, and centrifuged. The precipitate was then suspended in $0.2 v$ of heated extract and centrifuged again after freezing and thawing. The supernatant fluid, which was usually turbid and contained most of the activity, was acidified, centrifuged, and washed with water as previously. The precipitate ("second precipitate") was suspen. ded in $0.05 v$ of $0.015 M$ Tris-maleate buffer of $\mathrm{pH}$ 7.4 containing $0.005 M$ EDTA.

The activity of these preparations decreased about $50 \%$ after storage overnight at $-15^{\circ}$. More $3 t a k l e$ preparations were obtained by lyophilizing th: "second precipitate" and extracting with $0.05 v$ of $0.1 \mathrm{M}$ pyrophosphate buffer of $\mathrm{pH} 8$ containing $0.65 \mathrm{mM}$ reduced glutathione. The latter preparations were completely colorless and transparent and were stable for at least a week stored at $\mathrm{pH} 7$ and $-15^{\circ}$. The

\section{Effect of Increasing Enzyme Concentration}

As shown in Fig. 1, increasing amounts of UDP were formed with increasing amounts of enzyme. It may be noted that for practical reasons the test system contained only 0.23 $\mu$ mole UDPG, so that a linear relation was not to be expected. Furthermore, inhibition by UDP probably influences the course of the reaction.

\section{TABLE II \\ Stoichiometry}

Complete system as described in text, but with amounts doubled and $0.072 \mathrm{mg}$. glycogen.

\begin{tabular}{|c|c|c|c|}
\hline & $\begin{array}{c}\text { UDPG } \\
\text { disappea- } \\
\text { rance }\end{array}$ & $\begin{array}{l}\text { UDP } \\
\text { formed }\end{array}$ & $\begin{array}{l}\text { Glycogen } \\
\text { formed }\end{array}$ \\
\hline & $\boldsymbol{\beta}_{\mathrm{mole}}$ & $\mu$ mitale glucose & $\mu$ mole \\
\hline Complete system & 0.13 & 0.13 & 0.12 \\
\hline No G 6-P & 0.05 & 0.03 & 0.05 \\
\hline No glycogen & 0.015 & 0.02 & - \\
\hline
\end{tabular}

\section{TABLE I}

Results of the Purification Frocedure

Micromoles/hr./mg. protein

\begin{tabular}{lccc}
\hline & $\begin{array}{c}\text { Crude } \\
\text { extract }\end{array}$ & $\begin{array}{c}\text { Purified } \\
\text { preparation }\end{array}$ & $\begin{array}{c}\text { Ratio } \\
\text { Purified/crude }\end{array}$ \\
\hline UDP formation & 1.4 & 17.5 & 12.5 \\
Phosphorylase & 75 & 34 & 0.45 \\
Amylase (in glucose equivalents) & 0.02 & 0.018 & 0.9 \\
Protein concentration (mg. $\mathrm{ml}$. ) & 38.7 & 8.2 & - \\
\hline
\end{tabular}

results obtained in the purification by the second procedure are shown in Table $I$. The purification obtained in that experiment was 12-fold with respect to protein, and the yield was about $10 \%$. In other preparations the purification ranged from 20to 40 -fold.

\section{RESULTS \\ Stoichiometry}

The stoichiometry of the reaction catalyzed by the glycogen-forming enzyme is shown in Table II. It may be observed that, in the complete system, for each mole UDPG that was utilized about 1 mole UDP was formed and 1 mole glucose was added to glycogen. In the absence of G-6-P or glycogen, the chemical changes were much smaller.

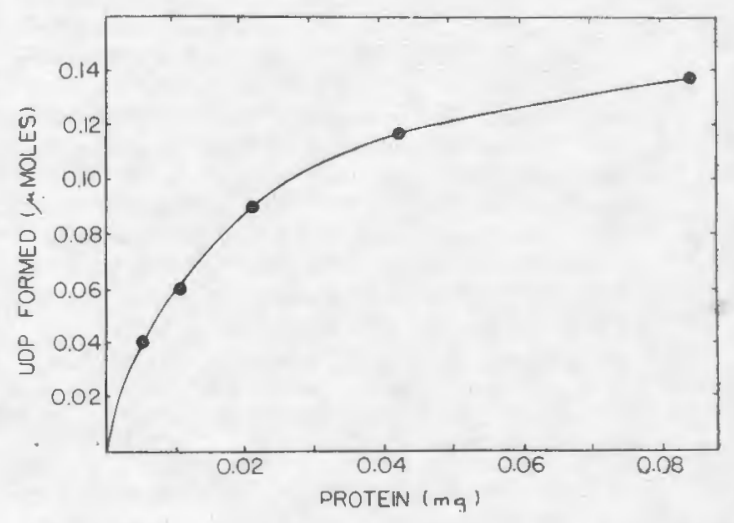

F1c. 1. The effect of enzyme concentration on the formation of UDP. Standard system as described in text. 


\section{Effect of UDPG Goncentration}

The course of the reaction with different UDPG concentrations is shown in Fig. 2. From these values, initial rates were calcuk lated as described under Methods, and the method of Lineweaver and Burk (18) was applied. The value obtained for the Michaelis constant, which should be considered only approximate, was $5 \times 10^{.4} \mathrm{M}$. It may be mentioned for comparison that the $K_{m}$ for G1-P in the phosphorylase reaction is $5.7 \times$ $10^{-3} M(19)$.

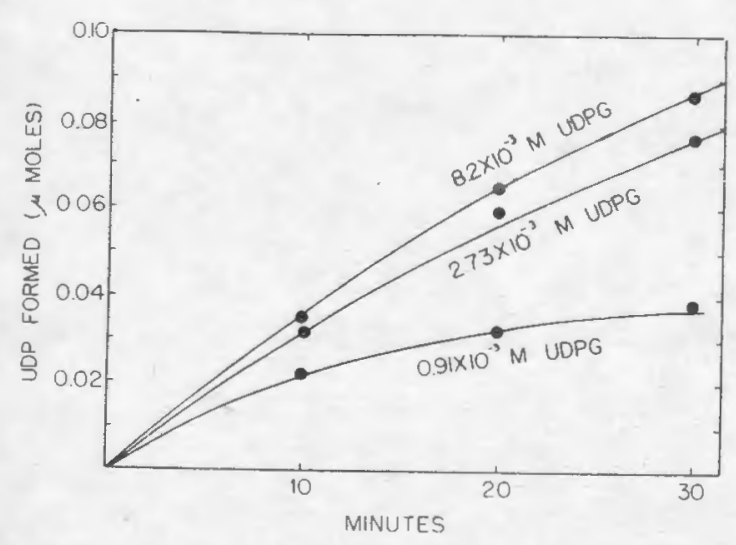

Fic. 2. Time curves with different amounts of UDPG. Standard system as described in text.

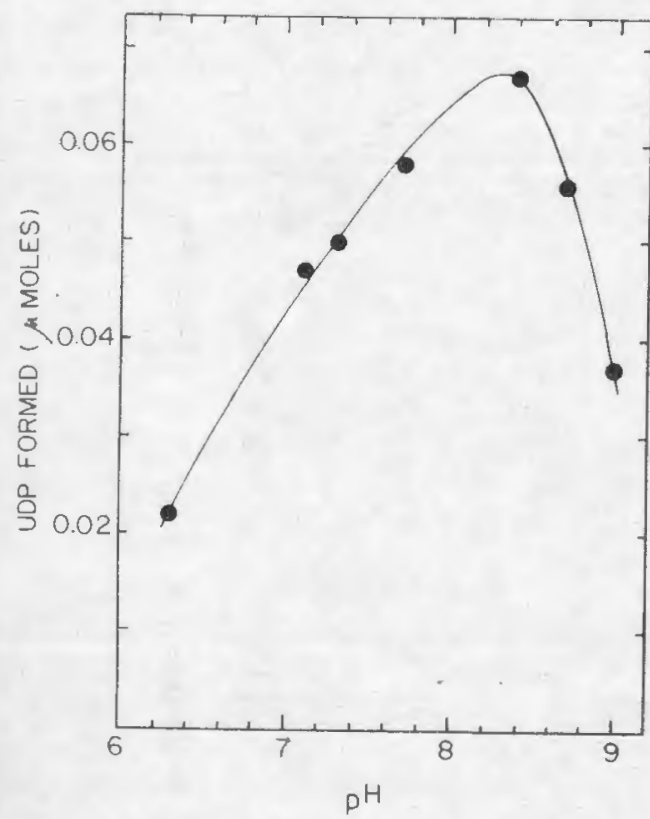

Fic. 3. pH -activity curve. Standard system as described in text, with Tris-maleate buffers of different $\mathrm{pH}$. The final $\mathrm{pH}$ was checked on aliquots with a glass electrode. The solutions were neutralized before proceeding to the enzymic estimation of UDP.

\section{pHOptimum}

As shown in Fig. 3, the $\mathrm{pH}$ for maximal activity in Tris-maleate buffer was 8.3 .

\section{Primer Requirements}

Figure 4 shows the effect of glycogen concentration on the rate of UDP formation from UDPG. The results of experiments employing different polysaccharides as primers are shown in Table III. Application of a first-order equation to such results gave values which changed greatly with time so that the percentages given in Table III were calculated from single time values and are probably not strictly proportional to priming ability. It may be observed that the primer requirements of the glycogen-forming enzyme are not very different from those of muscle phosphorylase. That is, the best primer is glycogen and its activity decreases after degradation. A more detailed study will be required to determine whether the differences observable in 'Table III are in fact real.

Substances which failed to give any detectable stimulation when tested as primers were: glucose, mannose, maltose, lactose, cellobiose, trehalose, raffinose, melibiose, and gentiobiose. Commercial dextrin (Difco) produced a slight activation.

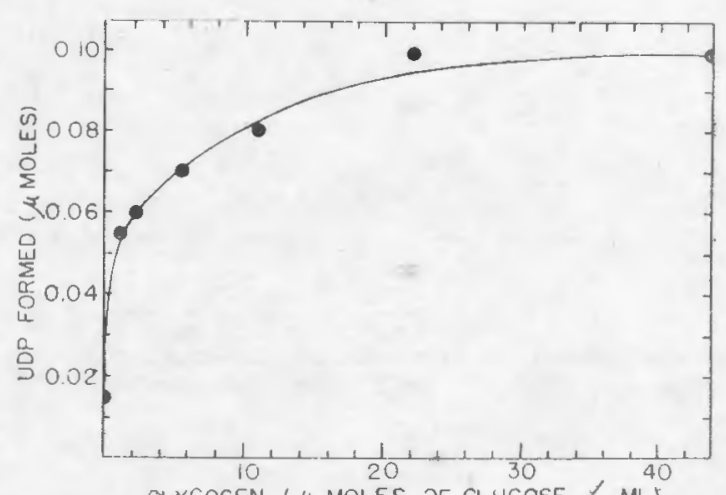

GLYCOGEN ( $\mu$ MOLES OF GLUCOSE $/$ ML)

Fic. 4. The effect of varying glycogen concentration on enzyme activity. Standard system as described. in text. 
TABLE III

\section{Activating Effect of Different Polysaccharides}

The results are expressed in per cent activation in relation to glycogen. The final concentration of polysaccharide was $5.4 \mathrm{mg} . / \mathrm{ml}$. in every case. Such a concentration of giycogen was just enough to produce maximal activity. All activities were tested with the same enzyme preparation. Numbers in brackets represent a second experiment. Incubation time: $30 \mathrm{~min}$.

\begin{tabular}{lrr}
\hline \multicolumn{1}{c}{ Polysaccharide } & $\begin{array}{c}\text { UDP formation } \\
\text { from UDPG }\end{array}$ & $\begin{array}{c}\text { Pi formation } \\
\text { from G-1-P }\end{array}$ \\
\hline Glycogen & 100 & 100 \\
Phosphorylase limit dextrin from glycogen & $59(52)$ & $28(20)$ \\
$\beta$-Amylase limit dextrin from glycogen & $30(31)$ & $15(20)$ \\
Glycogen treated with $\alpha$-amylase & $0-$ & $6-$ \\
Commercial soluble starch (blue with iodine) & $17(20)$ & $5(10)$ \\
Soluble starch b (red with iodine) & $19(13)$ & $0(0)$ \\
Potato starch (heated in alkali) & $59(48)$ & $9(20)$
\end{tabular}

a Prepared as described by Hestrin (20).

$b$ Obtained by treatment with acid according to Lintner (21).

\section{Activators and Inhibitors}

Phloridzin at $3.3 \times 10^{3} \mathrm{M}$ concentration inhibited $48 \%$. At the same concentration the inhibition of phosphorylase was $42 \%$ These vaiues were obtained from the change in initial rates calculated as described under Methods. Witl glucose at $0.05 \mathrm{M}$ concentration, the inhibition was $52 \%$, as compared to $72 \%$ for phosphorylase. The effect of added UDP was tested both by the standard method and by measuring glycogen formation. At $10^{-3} M$ of added UDP, the inhibition was $31 \%$; and at $5 \times 10^{-4} M$ it was $18 \%$.

The reaction was inhibited $80 \%$ by $0.2 \mathrm{M}$ potassium borate and $58 \%$ by $0.1 \mathrm{M} \mathrm{KCN}$. Two antidiabetic substances 1-p-tolysulfonyl3-butylurea and 1-( $p$-aminobenzenesulfonyl)-9butylurea $(0.2 \%$ final concentration) inhibited slightly (15 and $8 \%$, respectively). Cysteine or reduced glutathione produced a slight activation on some enzyme preparations. The following substances did not change the activity: $\mathrm{Mg}^{+}+, \mathrm{G}-1-\mathrm{P}$, adenosine triphosphate, adenosine 5'-monophosphate, galactose 1 phosphate, and insulin.

\section{The Action of Glucose 6-Phosphate}

Partially purified preparations of the glycogen-forming enzyme were found to be activated by heated extracts. Heated pigeon muscle extracts were particularly active. The active substance proved to be stable in acid, labile in alkali, and behaved as an acid when treated with anion-exchange resins. Many known substances were tested as possible substitutes for the heated extract. Of these G-6-P and fructose 6-phosphate proved to be active. Since the preparation contained an active phosphoglucoisomerase, it could not be decided which of the two produces the activation. A sample of G-6-P obtained by chemical synthesis was found to be active. Many other substances were tested as possible substitutes for G-6-P. The following were ineffective: glucose, maltose, trehalose, fructose 1phosphate, trehalose phosphate, sucrose phosphate, lactose, citrate, G-1-P, adenosine triphosphate, adenosine 5'-monophosphate, glutamic acid, inorganic phosphate, and galactose 1-phosphate. Activation was obtained with glucosamine 6-phosphate and with galactose 6-phosphate. The sample of the latter was contaminated with G-6-P, but the amount appeared to be too small to account for the activation.

A curve showing the formation of UDP with different G-6-P concentrations is shown in Fig. 5. Half-maximal velocity was attained at about $6 \times 10^{4} M$ concentrations of $\mathrm{G}$ 6-P. In order to obtain information on the mechanism by which G-6-P increases the rate of reaction, some experiments were carried out with labeled compounds. As shown in Table IV, while the radioactivity of $\mathrm{C}^{14} \mathrm{UD}$. PG was recovered in the glycogen, that of 


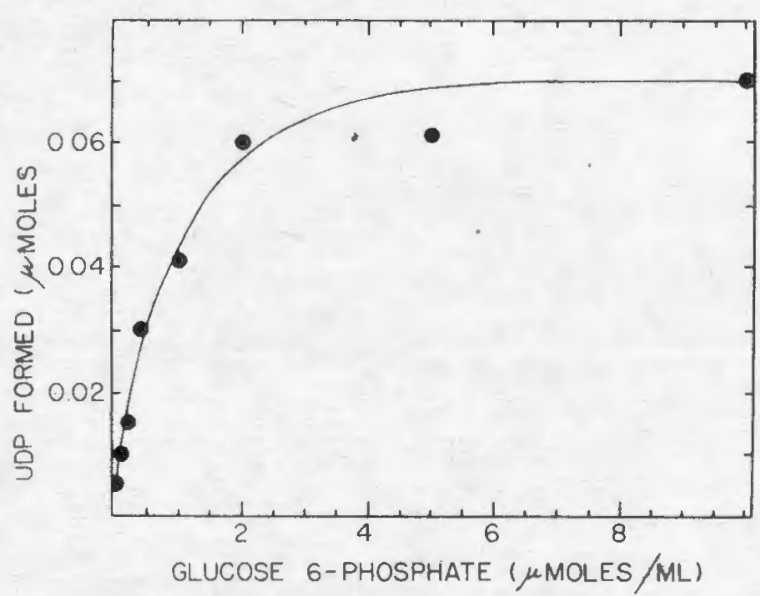

Fic. 5. - The effect of changing G-G-P concentration. Standard system as described in text.

\section{TABLE IV}

\section{Incorporation of Radioactivity inlo the Glycogen}

Complete system as described in text except for the additions indicated and that the amount of glycogen was increased to $1.2 \mathrm{mg}$.

The reaction was stopped by adding $0.9 \mathrm{ml}$. of $33 \% \mathrm{KOH}$. After heating $20 \mathrm{~min}$. at $100^{\circ}$, the gly. cogen was precipitated with $1.25 \mathrm{mi}$. ethanol, boiled, centrifuged, reprecipitated, and plated for counting the radioactivity.

\begin{tabular}{|c|c|c|c|c|}
\hline \multicolumn{4}{|c|}{ Additions } & \multirow{3}{*}{$\begin{array}{l}\text { Counts/min. } \\
\text { in glycogen }\end{array}$} \\
\hline \multicolumn{2}{|c|}{ UDPG } & \multicolumn{2}{|c|}{ G-6-P } & \\
\hline$\mu$ mole & rounts/min. & $\mu$ mole & counts $/ \mathrm{min}$. & \\
\hline 0.16 & 4,950 & 0.80 & 0 & 2,550 \\
\hline $0.16^{\mathrm{a}}$ & $4,950^{\mathrm{a}}$ & 0.80 & 0 & 0 \\
\hline 0.25 & 0 & 0.43 & 51,500 & 120 \\
\hline $0.25^{a}$ & $0^{\mathrm{a}}$ & 0.43 & 51,500 & 30 \\
\hline
\end{tabular}

adiled after incubation.

TABLE V

Nondisappearance of $\mathrm{G}$ 6-P

Standard system as described under Methods except for the G-6-P concentration.

\begin{tabular}{lrccc}
\hline Incubation & tinuc & f-6-P estimation & UDP formed \\
& min. & $\mu_{\text {Imole }}$ & $\mu$ mole \\
Complete system & 0 & 0.097 & 0 \\
Complete system & 30 & 0.098 & 0.057 \\
No glycogen & 30 & 0.099 & 0.003 \\
\hline
\end{tabular}

$\mathrm{C}^{114}$ G-6-P was not. Moreover, estimations of G-6-P + fructose 6-phosphate showed that there was no measurable change in concentration during the reaction (Table $\mathrm{V}$ ).

The assumption that hexose phosphate might act as primary acceptor of the glucose residue and that a disaccharide phosphate would then serve as donor to the glycogen, was examined by several methods. One was to add phosphopyruvate and pyruvate kinase during the reaction in order to favor the first step by removing the UDP. Even under these conditions the reaction required a polysaccharide primer, showing that the first step would not take place without the second, or that only one step is involved in the overall reaction. Other experiments consisted in adding disaccharide phosphates such as sucrose or trehalose phosphate instead of UDPG and testing for increase in glycogen. The results were negative.

\section{Radioactive Glycogen}

Incubation of $\mathrm{C}^{14}$ UDPG led to the labeling of the glycogen. In a typical experiment 1.2 $\mu$ moles of $\mathrm{C}^{14}$ UDPG $(12,400$ counts/ min.) were incubated with an eightfold dose of the standard mixture containing $4.8 \mathrm{mg}$. glycogen. After $30 \mathrm{~min}$. at $37^{\circ}$ the mixture was boiled in alkali, precipitated with 1.25 vol. ethanol, and reprecipitated. An aliquot was plated for measuring radioactivity. The number of counts per minute in the glycogen fraction for the total sample was 10,000 . That is, the incorporation reached about $80 \%$. It may be mentioned that the $\mathrm{C}^{14}$ UDPG preparation contained about $25 \%$ UDP-galactose, so that the incorporation obtained 
was complete within experimental errors. Controls in which the reaction was stopped at $t=0$ gave no radioactivity.

\section{Reaction Products}

The method used for the estimation of UDP is not very specific. Other nucleoside diphosphates and also adenosine monophosphate are active in this test system. However, uridine monophosphate is inert. In onder to check the formation of UDP in the enzymic reaction, the products were run on paper with an ethanol-ammonium acetate solvent of $\mathrm{pH} 7.5$ (22). A spot with the same mobility as UDP was observed in the zone corresponding to the complete sample, but not in that of controls where the reaction was stopped at zero time or incubated without UDPG. Furthermore, it may be mentioned that no inorganic phosphate was found to be liberated in the reaction, and that no formation of oligosaccharides could be detected by paper chromatography.

As to the characterization of the polysaccharide formed in the reaction, the usual methods could not be used because only small amounts of UDPG were available. Therefore enzymic degradation and paper chromatogra- phy were utilized. The procedure consisted in isolating the glycogen formed from Cut UDPG as previously described. The radioactive glycogen obtained was treated with $\beta$-amylase which is known to hydrolyze alternate $1 \rightarrow 4 \alpha$-linkages yielding maltose. The reaction mixture was then treated with 3 vol. methanol. The soluble portion which contained all the radioactivity was run on paper with the pyridine-butanol-water solvent (6: 4:3) (23). As shown in Fig. 6 $A$, the product obtained behaved like maltose with a trace of glucose. All the radioactivity was found in the disaccharide spot. Since the afore-mentioned solvent did not separate the disaccharides, a sample which had been chromatographed was wetted with borate buffer and submitted to electrophoresis. As shown in Fig. $6 B$, the radioactivity was found in a spot having the same mobility as maltose. Electrophoresis was carried out after paper chromatography because in that manner the interference of salts and residues of protein was obviated.

As an additional test, the product obtained by the action of $\beta$-amylase was treated with a maltase-containing yeast extract. As shown in Fig. 7, the radioactivity appeared in a spot migrating like glucose.

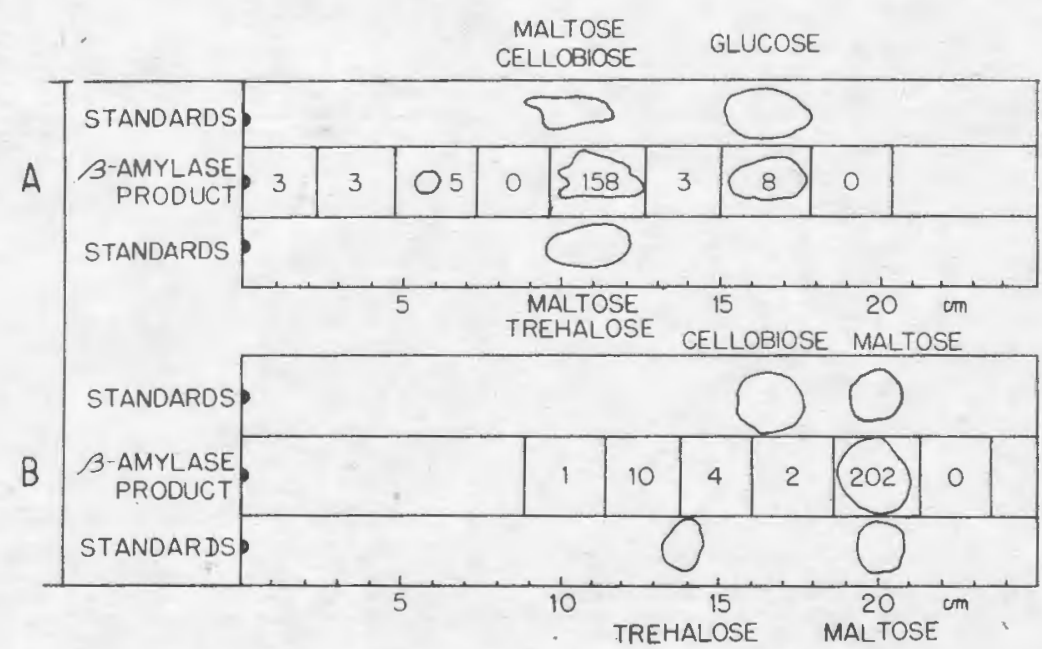

Fis. 6. - A: Paper chromatography of the product obtained by the action of $\beta$-amylase on the glycogen formed from radioxactive UDPG. i he glycogen was obtained as described in text. An aliquot was treated with $\beta$-amplase at pH $6(20)$ for $20 \mathrm{hr}$. at $37^{\circ}$. Three volumes of methanol was added. The supernatant which contained all the radioactivity was spotted on paper and run with the butanol-pyridine-water solvent. The radioactivity of the sugar spots was then detected as described in text. The squares in the graph show how the papers were cut and the numbers represent counts per minute after substracting background.

$n$ : Same as $A$, but after chromatography the paper was wetted with $0.05 \mathrm{M}$ borate bufer of $\mathrm{pH} 9$ and submitted to electrophoresis at $600 \mathrm{v}$. for $6 \mathrm{hr}$. 


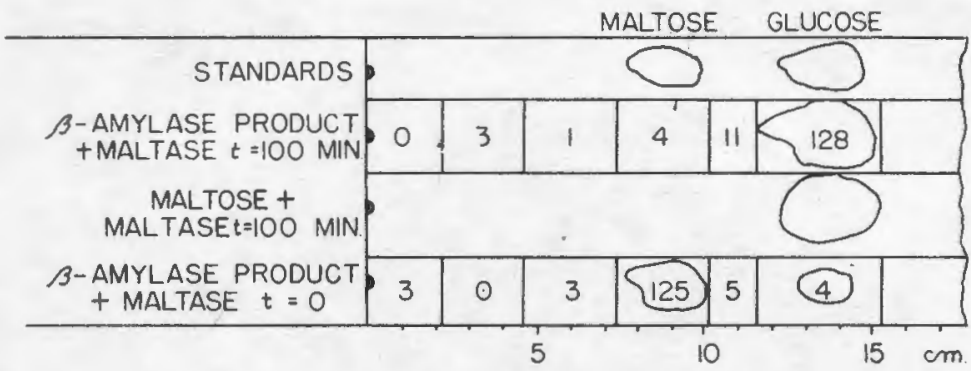

FIG. 7. - Paper chromatography of the product obtained by the action of $\beta$-amylase on radioactive glycogen submitted to the subsequent acion of a maltase containing yeast extract. General procedure as in Fig. 5.

In other experiments the radioactive glycogen was degraded with phosphorylase and excess inorganic phosphate (20). On precipitation with 3 vol. methanol, no radioactivity remained in the precipitate containing the limit dextrin. The soluble portion was freed from methanol by exaporation and separated into two fractions by $\mathrm{ZnSO}_{4}$ and $\mathrm{Ba}(\mathrm{OH})_{2}$ precipitation. The precipitate containing G-1-P was hydrolyzed with acid (24), and the free sugar formed was chromatographed on paper with the butanol-pyridine-water solvent. Radioactivity was found only in the glucose spot.

\section{Distribution}

The activity of extracts of different rat organs is shown in Table VI. It may be observed that more activity is found in muscle, heart, and liver than in the other organs. Positive results were also obtained with pigeon liver and muscle and with rabbit muscle.

\section{Discussion}

There are some facts which indicate that the classical scheme for glycogen synthesis may not be correct since it implies the action of phosphorylase, and the ratio of inorganic phosphate to G-1-P as measured in who-

TABLE VI

Distribution in Different hai Organs

Results expressed as micromoles UDP formed/hr./ g. tissue. Organs were homogenized in 3 vol. water.

\begin{tabular}{lrll}
\hline Muscle & 220 & Spleen & 37 \\
Heart & 166 & Kidney & 31 \\
Liver & 187 & Lung & 36 \\
Brain & 32 & &
\end{tabular}

le tissues is usually too high for net synthesis to take place (25). Furthermore, agents which cause glycogen degradation produce a concomitant increase in phosphorylase concentration. Thus the glycogenolytic action of epinephrine $(26,27)$ glucagon, and high $\mathrm{Na}+$ ions (28) has been attributed to an increase in phosphorylase activity. Other facts have also been interpreted as meaning that phosphorylase functions mainly in the degradation of glycogen $(25,29)$. If these conclusions are correct, then some other mechanism or mechanisms should be involved in glycogen synthesis and the enzyme described in this paper might well serve this purpose. In the intact rat liver the rate of glycogen formation is about $30 \mu$ moles/hr./g. (30) and, as shown in Table VI, liver extracts under optimal conditions can catalyze the transfer of about $190 \mu$ moles glucose from UDPG $/ \mathrm{hr}$./ g. tissue. The values for muscle are 5-17 (31) and 220, respectively. In the whole organ the enzyme is, presumably, not working at saturating concentrations of substrate and activator so that the two values might be in fair agreement.

It may be mentioned that tissues have much more phosphorylase than the glycogen-forming enzyne; thus when the rate of glycogen formation from UDPG and from G-1-P was compared in crude muscle extracts under optimal conditions and in the presence of activators (G-6-P and adenylic acid, respectively), it was found that the latter process (phosphorylase reaction) was 20-50 times faster.

The tests which have been carried out on the radioactive glycogen formed from $\mathrm{C}^{1 / 4}$ UDPG indicate that the glucose residue becomes attached by $\alpha(1 \rightarrow 4)$ linkage. This is 
the same type of linkage which is hydrolyzed by phosphorylase.

As to the mechanism by which G-6.P increases the activity of the glycogen-forming enzyme, no clue was obtained. The effect was also obtained with fructose 6-phosphate, glucosamine 6-phosphate, and galactose 6-phosphate. No indication in favor of the intermediary fornation of a disaccharide phosphate could be 'shown.

\section{SUMMARY}

An enzyme which leads to the formation of glycogen according to the equation:

\section{REFERENCES}

1. Leloir, L. F., and Cardini, C. E., $J$. Am. Chem. Soc. 79, $6340(1957$.

2. Dubois, M., Gillfs, K. A., Hamilton, J. K., ReBers, P. A., ANd SMith, F., Anal. Chem. 28, $350(1956)$.

3. Montgomery, R., Arch. Biochem. Biophys. 67; 378 (1957).

4. Somogri, M., in "Methods in Enzymology" (S. P. Colowick and N. O. Kaplan, eds.), Vol. III, p. 3. Academic Press, New York, 1957.

5. Trevelyan, W. E., and Harrison, J. S. Biochem. $J$. 50, 298 (1952).

6. Cabib, E., and Lelorr, L. F., J. Biol. Chem. 231, 259 (1958).

7. Strominger, J. L., Maxweli, E. S., Axelrod, J., and Kalckar, H. M., J. Biol. Chem. 224, 79 (1957).

8. Cori, G. T, Illingworth, B., and Keller, J. P., in "Methods in Enzymology" (S. P. Colowick and N. O. Kaplan, eds.), Vol. I, p. 200. Academic* Press, New York, 1955.

9. Kunitz, M., And McDonald, M. R., J. Gen. Physiol. 29, 393 (1945-46).

10. Warburg, O.. and Christian, W., Biochem. Z. 310 , 384 (1941).

11. Park, J. T., And Johnson, M. J., J. Biol. Chem. 181,149 (1949).

12. KORNBFR, A., AND HORFCKFR, E. L., in "Methods in Enzymology" (S. P. Colowick and N. O. Kaplan, eds.), Vol. I, p. 323, Academic Press, New York, 1955

13. Trevelyan, W. E., Procter, D. P., and HarriSon, J. S., Nature 166, 444 (1950).

14. Pontis, H. G., Cabir, E., and Leloir, L. F., Biochim. et Biophys. Acta 26, 146 (1957).
UDPG + primer $\neg$ UDP + glucosyl $\alpha(1 \rightarrow 4)$ primer has been studied.

The optimal conditions for activity were determined with a partially purified preparation from rat muscle. The reaction requires the presence of a polysaccharide as primer and is strongly activated by hexose 6-phosphates. Using UDPG labeled in the glucose moiety, it was found that the radioactivity was transferred to the glycogen from which it could be removed as maltose with $\beta$-amylase or as G-1-P with phosphorylase. Thus it seems that the glucose residue becomes linked $\alpha(1 \rightarrow 4)$ to the polysaccharide. Several inhibitors were tested as well as the occurrence of the enzyme in different organs.

15. Trucco, R. E., Nature 174,:103 (1954)

16. Ballou, G. A., And Luck, J. M., J. Biol. Chem. 139, 233 (1941).

17. Wfidenhagen, R., in "Die Methoden der Fermentforschung" (E. Bamann and K. Myrbãck, eds.), Band II, p. 1749. George Thieme Verlag, Leipzig, 1941.

18. Lineweaver, H., and Burk, D., J. Am. Chem. Soc. 56, 658 (1934).

19. CorI, C. F., Cori, G. T., And Grfen, A. A., J. Biol. Chem. 151, 39 (1943).

20. Hfstrin, S., J. Biol. Chem. 179, 943 (1949).

21. Vanino, L., "Handbuch der Präparativen Chemie," Band II, p. 204. Ferdinand Enke, Stutgart, 1937.

22. Paladini, A. C., ANd Leloir, L. F., Biochem. J. 51, 426 (1952).

23. Jeanes, A., Wise, C. S., and Dimler, R. J., Anal. Chem. 23, 415 (1951).

24. Cardini, C. E., and Leloir, L. F., Arch. Biachem. Biophys. 45, 55 (1953).

25. Niemeyfr, H., "Metabolismo de los hidratos de carbono en el hígado," Universidad de Chile, Santiago, 1955.

26. Sutherland, E. W., and Cori, C. F., J. Biol. Chem. 188,531 (1951).

27. Sutherland, E. W., Ann. N. Y. Acad. Sci. 54, 693 (1951).

28. Cahill, G. F., Ashmore, J., Zottu, S., And HastINGS, A. B., J. Biol. Chem. 224, 237 (1957).

29. Beloff-Chain, A., Catanzaro, R., Chain, E. B., Masi, I., Pocchiari, F., and Rosst, C., Proc. Roy Soc. (London) 143, 481 (1955).

30. Catron, L. F., and Lewis, H. B., J. Biol. Chem. $84,553(1929)$.

31. Stadie, W. C., Haugaird, N., and Vauchan, M., J. Biol. Chem. 200, 745 (1953). 